\begin{tabular}{|c|c|c|}
\hline & $\begin{array}{c}\text { European Association for the } \\
\text { Development of Renewable Energies, Environment } \\
\text { and Power Quality (EA4EPQ) }\end{array}$ & $\begin{array}{l}\text { International Conference on Renewable Energies and Power Quality } \\
\text { (ICREPQ'12) } \\
\text { Santiago de Compostela (Spain), 28th to 30th March, } 2012\end{array}$ \\
\hline
\end{tabular}

\title{
Pre-Feasibility Analysis of a Desalination Plant Powered by Renewable Energy in Thira, Greece
}

\author{
Antonio E. Alanís-Noyola1, Ashreeta Prasanna1, Thibault Rannou1, Luis Rojas-Solórzano2 \\ ${ }^{1}$ Department of Environmental and Energy Engineering \\ Ecole des Mines de Nantes \\ 4 Rue Alfred Kastler, 44300 Nantes (France) \\ Phone number:+46 760691822, \\ e-mail: \\ thibault.rannou@gmail.com, antonioealanis@gmail.com, ashreeta@gmail.com,rrojas@usb.ve \\ ${ }^{2}$ Universidad Simón Bolívar, Dept. of Energy Conversion and Transport. Caracas-Venezuela.
}

\begin{abstract}
Renewable energy desalination is an excellent solution for areas lacking electrical grid connection or any other source of energy. However, the economic feasibility of renewable energy desalination compared to desalination using grid energy has not been extensively researched. This report presents a technical and financial pre-feasibility assessment for solar and wind energy desalination, compared to conventional desalination in Thira island (Greece).
\end{abstract}

The technical assessment involves design of a desalination unit with a capacity of $1000 \mathrm{~m}^{\wedge} 3$ per day, using ROSA software. The financial feasibility analysis is carried out using RETScreen, a 'Clean Energy Project Analysis Software'. The report presents two case scenarios: Solar and Wind power compared to diesel generators, to desalinate seawater.

The outcome of this report is to use our feasibility analysis to support implementation of renewable energy desalination in large and medium population locations, besides rural areas, located in geographic regions similar to Thira island. The results of our feasibility analysis reveal a good potential for the development of renewable energy desalination projects: implementing the wind energy option would generate a net present value of $732,295 €$ with an attractive payback period shorter than 6 years.

\section{Key words}

Desalination, Renewable energy, Pre-Feasibility, RET Screen, ROSA

\section{Introduction}

Nowadays, there are around three billion people around the world with no access to clean drinking water [1]. The burning of fossil fuels as main source of energy is slowly carrying the world to a dangerous situation. Not only will we reach a time when these resources will be exhausted but long before that the environment will be affected irreversibly. The only way to abate this situation is to promote the use of renewable energies. However, this objective will not be achieved unless it is proven that the change is economically feasible.

At the same time, the world is heading towards a global water scarcity situation. While digging wells is a solution used around the world, there are some places where this is not possible or not economically attractive. Islands, in particular, face a situation of water and energy shortage, due to their lack of connectivity. However, coastal areas and islands have availability of renewable resources, which could help to solve their energy and water shortage problems as well as provide an important source of income for the local government.

Our project focuses on the utilisation of wind and solar energy for desalination of seawater. Renewable Energy Desalination (RES) has not been implemented extensively because lack of knowledge whether the project will be financially profitable and insufficient incentives offered by local governments. This paper evaluates the financial feasibility of implementation of RES on Thira, an island in Greece where there are plans to build a desalination plant. First a short overview of the location with water and energy situation in Thira is given. Then the selection of the desalination technology and design requirements of the desalination unit is presented. Finally an economic analysis of different combinations of RES is presented, showing that RES is economically feasible in Thira and other locations in the area that are not connected to a central grid electricity supply.

\section{Background}

Thira is the official name of Santorini which is an island located in the southern Aegean Sea, about $200 \mathrm{~km}$ southeast from the Greek mainland. Due to the hot desert climate, Thira has to face aridity combined with few 
natural water resources. Only a couple of water reserves have long been the existing solution to satisfy the local water demand without taking into account the significant increase due to tourism. In recent years, a desalination plant has provided running and drinking water to most houses. A local company named TEMAK has set up this plant. The Greek Interior Ministry has announced on 5th May 2011 that a budget of 4.86 million EUR will be assigned to 11 island municipalities in Greece, to cover operating costs of desalination of water. The municipalities are Nyssiros, Symi, Ithaca, Thira, Mykonos, Paros, Sifnos, Syros, Ermoupoli, Tinos, Oinousses and Chios. Our project, located in Thira, can benefit from this assigned budget and thus,sufficient financial incentives exist for project start-up and operation.

Looking at the energy supply, the electricity required by the desalination plant is currently produced by internal combustion reciprocating engines owned by the Public Power Corporation (PPC), which is the biggest electric power company in Greece. Thira as many other islands is facing currently power outage issues as well as an increasing demand about to exceed the supply by the engines used. To reach a stable electrical system able to provide a smooth future supply to the Cyclades islands, the Greek government has decided to connect the Cyclades islands to the mainland's grid. In addition, Thira has an annual daily solar radiation of $5.24 \mathrm{kWh} / \mathrm{m}^{2} /$ day and annual average wind speed of $5.4 \mathrm{~m} / \mathrm{s}$, which is sufficient for renewable energy development [2].

\section{Methodology}

The approach to the project involved four main steps:

- Choosing a desalination technology that can provide drinking water from an input feed of seawater.

- Understanding the water capacity demands of the community in which the Renewable Energy Desalination Plant operates.

- Design of the desalination system using Reverse Osmosis System Analysis (ROSA) design software.

- Economic Analysis of various renewable energy sources to power the Desalination Plant using RETScreen software.

\section{Desalination Technology - Choice and Design}

\section{A. Choice of a desalination technology}

The strengths and weaknesses of the available desalination technologies were analysed to enable us to choose the appropriate technology for our project [3]. Reliable cost effective technologies suitable to the local area would ensure the financial success of desalination plant.

The a comparison was carried out between Muti Stage Flash (MSF), Electrodialysis Reversal (EDR) and Reverse Osmosis process.
When using the EDR process for desalination, the energy requirements are proportional to the water salinity and thus this process is more economically feasible when the salinity of the feed water is lower than $6000 \mathrm{ppm}$ of dissolved solids. Considering that the salinity of seawater is generally included within the range 15000 to 50000 ppm of TDS, EDR is more suitable to treat brackish water rather than seawater.

When choosing between the MSF and RO technologies, an important factor is the required energy demand for the desalination technology as well as the use of a mature technology when designing a decentralized small-scale desalination unit.

Table I. - Key Operational data for MSF and RO

\begin{tabular}{|l|l|l|}
\hline Criteria/Technology & MSF & RO \\
\hline $\begin{array}{l}\text { Electrical energy }(\mathrm{kWh} / \\
\left.\mathrm{m}^{3}\right)\end{array}$ & 35 & $0.4-7$ \\
\hline $\begin{array}{l}\text { Product water quality } \\
\text { (ppm TDS) }\end{array}$ & $<10$ & $<500$ \\
\hline
\end{tabular}

Another factor in choosing desalination technologies to be coupled with renewable energy is to look at already existing projects that are operating successfully. The following chart sums up the small-scale desalination units empowered by renewable energy. The most commonly used combination is PV with RO followed by wind [4].

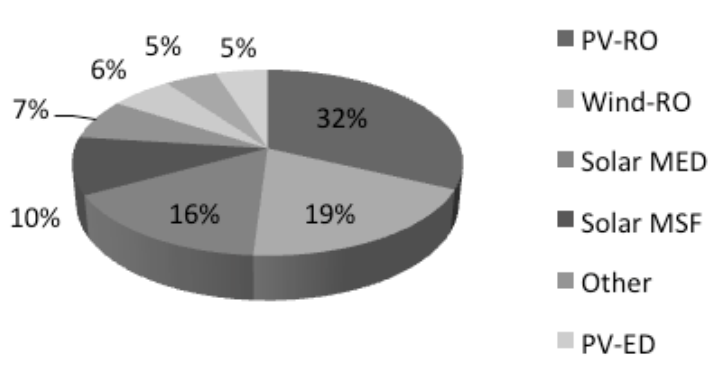

Fig. 1. Percentage of existing units using desalination technologies coupled with renewable technologies

Source: Eftihia Tzen (CRES, Greece), Overview of the desalination technologies powered by renewable energies.

For all of these reasons, we chose Reverse Osmosis for the Desalination System technology, using Wind and Solar Energy to operate the unit.

\section{B. Modelling of a Desalination unit}

Initial modelling of a desalination plant was carried out using Reverse Osmosis System Analysis (ROSA) software. The purpose of using the software to model our system is to be able to have an idea of the number of stages required in the reverse osmosis desalination unit, 
operating pressure, the quality of the output water, energy requirement and related costs.

The flow rate of the feed in our small scale unit was set to $1000 \mathrm{~m} 3 /$ day. This value is considered to be sufficient for a community of approximately 2600 people, if we consider an average consumption of $300 \mathrm{~L}$ per day $(0.3$ cubic meters). This value is the average in Europe and the system modelling has been carried out with a higher estimate [5], keeping in mind that if water usage efficiency measures were implemented then the outcome would be to provide water to a greater number of people.

The outcome of the modelling gives an energy consumption requirement of $5 \mathrm{kWh} / \mathrm{m} 3$ and a $41.21 \%$ recovery rate. These values fall within the range of average values in the industry. From the daily consumption (1000 m3/day), the energy consumption per year is calculated which can be used for an economic feasibility analysis. Assuming that the desalination unit is working full-time 24/7, we obtain an energy consumption of 1,825 MWh per year.

\section{Economic Analysis}

In this project, RETScreen is used to evaluate if renewable energy desalination is a good alternative to diesel energy which is currently being used in the island of Thira. RETScreen Clean Energy Project Analysis Software is a unique decision support tool developed with the contributions from government, industry and academia by Natural Resources Canada in 1996. The software is used to evaluate the energy production and savings, costs, emission reductions, financial viability and risk for various types of Renewable-energy and Energy-efficient Technologies (RETs).

Modelling in RETScreen involves various steps and detailed information about the project. The software works on the principle of comparing an initial, "base case" scenario with the new, "proposed case" scenario. The financial evaluation is done on a comparative basis between the conventional energy source (grid or diesel engine) and the renewable energy, which in our case is wind and solar energy. The savings in costs by substitution of conventional energy by renewable energy, if any, are calculated, as well as a risk and sensitivity analysis. This allows preliminary decision making based on financial figures obtained.

\section{A. RETScreen Modelling}

RETScreen modelling involves input of various parameters based on the location, energy demand and type of renewable energy for the project on which the feasibility study is carried out.

Figure 2 describes the various steps involved in carrying out the feasibility analysis. The site conditions are determined based on data from NASA satellite information and wind conditions and solar radiation values are possible inputs to the model.

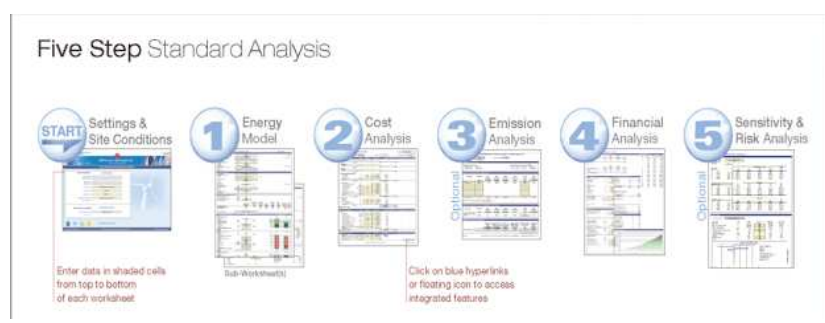

Fig. 2. Five Step analysis for evaluating economic feasibility of a project

At the start of modelling, the base case and proposed case scenarios are defined. The two case scenarios presented in the following sections have the base case as energy supply from two diesel generators and the proposed case as energy supply from wind and solar, respectively.

Step 1 involves selecting the base case and proposed case energy inputs for the project. In step 2, the initial, annual and periodic costs for the proposed case system are added, as well as credits for any base case costs that are avoided in the proposed case. The next step involves determination of the annual reduction in the emission of greenhouse gases stemming from using the proposed technology in place of the base case technology. After this the financial parameters related to the project such as GHG emission reduction credits, incentives, etc., are taken into account and the net present value of the project is calculated. Lastly the risk and sensitivity analysis determines the uncertainty. In the estimates of various key parameters that may affect the financial viability of the project.

The current set up for electricity generation on the island of Thira is a small electricity generation plant operating on diesel fuel. In our simulations, where the base case is electricity from the grid, the cost of electricity is the same as that on mainland Greece. In the base case where the electricity supply is from diesel generators, we have assumed that 2 diesel generators with a capacity of 1000 $\mathrm{kW}$ each. The diesel generators provide backup in the proposed case scenarios and no batteries are required for the renewable energy systems.

Two scenarios are presented in the following sections: CASE STUDY 1: OFF GRID WIND TURBINES CASE STUDY 2: OFF GRID SOLAR PANELS

Besides these, other case scenarios, which have been simulated are on grid wind turbines and on grid solar panels. The results from these scenarios are further discussed in section concerning alternative case studies.

\section{B. RETScreen scenarios}

\section{SCENARIO 1: OFF GRID WIND TURBINES}

In this case study for RETScreen modelling the base case consists of two diesel engines with a capacity equal to the entire demand of the desalination plant each.

The proposed case considers wind turbines (assumed attached to AC motors, which means they provide $220 \mathrm{~V}$ at $60 \mathrm{~Hz}$ ) will share the load with the current diesel engines. Three turbines of $50 \mathrm{~kW}$ each from the brand Atlantic Orient model AOC 15/50 with a height of $25 \mathrm{~m}$ and a swept area of $177 \mathrm{~m} 2$ were employed as energy 
supply. They provided the system with $422 \mathrm{MWh}$, which is more than the $20 \%$ of the total energy requirement. Figure 3 presents the schematics of this case study.

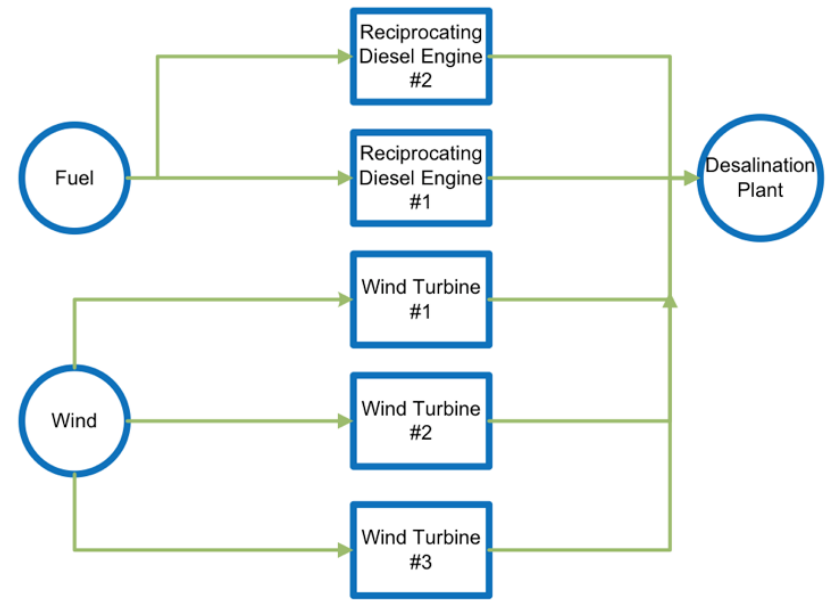

Fig. 3. Schematic of proposed case with wind turbines energy model

Table II. - Summary of wind turbines vs. diesel generation case study

\begin{tabular}{|l|l|}
\hline Total power demand: $1825 \mathrm{MWh}$ & Location: Thira, Greece \\
\hline & \\
Base case: & Efficiency of the engines: $95 \%$ \\
$1825 \mathrm{MWh} /$ year produced by 2 & Average wind velocity: $5.4 \mathrm{~m} / \mathrm{s}$ \\
reciprocating engine & Total initial costs:527,315€. \\
$\begin{array}{l}\text { Proposed case: } \\
422 \mathrm{MWh} / \text { year produced by wind }\end{array}$ & \\
energy & \\
$1403 \mathrm{MWh} /$ year produced by 2 & \\
reciprocating engines & \\
\hline
\end{tabular}

\section{SCENARIO 2: OFF GRID SOLAR PANELS}

The proposed case is solar panels along with an inverter which will share the load with the current diesel engine so that the fuel consumption is substituted. The panels provide approximately $20 \%$ of the energy required for desalination.

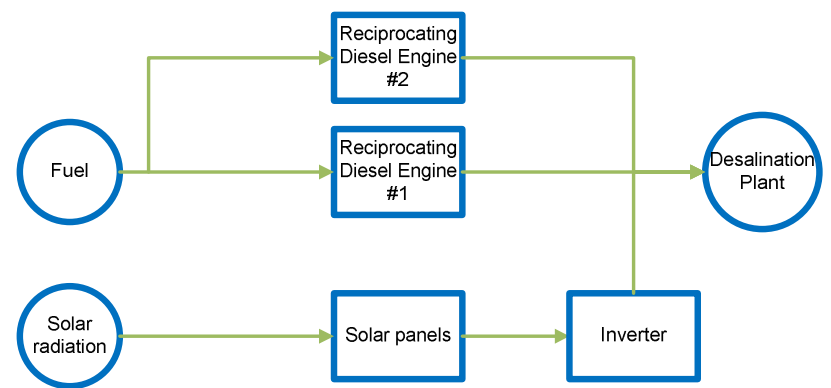

Fig. 4. Schematic of proposed case with solar panels

The chosen solar panels are manufactured by Atlantic Orient, and were selected because of their power capacity and relatively small size. The model is known as AOC $15 / 50-25 \mathrm{~m}$.

The nominal power capacity of each turbine, is $50 \mathrm{~kW}$ with a hub height of $25 \mathrm{~m}$, a rotor diameter of $15 \mathrm{~m}$ and a sweep area of $177 \mathrm{~m} 2$. After considering the array loses, airfoil losses and miscellaneous losses, as well as an availability of $95 \%$, we obtained a capacity factor of $32.2 \%$ and an amount of $422 \mathrm{MWh}$ produced per year.

\section{Results And Discussion}

\section{SCENARIO 1: OFF GRID WIND TURBINES}

\section{FINANCIAL OUTCOMES}

The IRR on equity after taxes and the Net Present Value are particularly attractive as it can be appreciated in Table 4.

Table 4. Summary of key financial figures

Key financial figures Value

IRR equity after taxes $\quad 30.0 \%$

IRR assets after taxes $\quad 17.6 \%$

NPV 732,295

Benefit-Cost ratio

The result of the financial feasibility study is encompassed in Fig. 5. The cumulative cashflows are very satisfactory: plus, the payback time shorter than 6 years is extremely attractive for a renewable energy project.

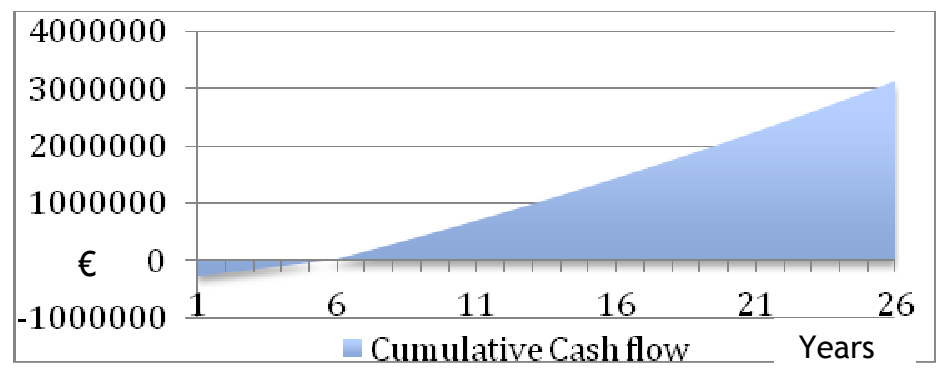

Fig. 5. Cumulative cash flow for wind turbine project

\section{RISK AND SENSITIVITY ANALYSIS}

The key figures of the risk analysis are highlighted in Fig. 6 . The effect of a set of five independent variables on the NPV value is analysed: initial costs, electricity export rate, debt interest rate, debt ratio and debt term. As seen from Fig. 6 the two most influencing factors are the initial costs and the electricity export rate.

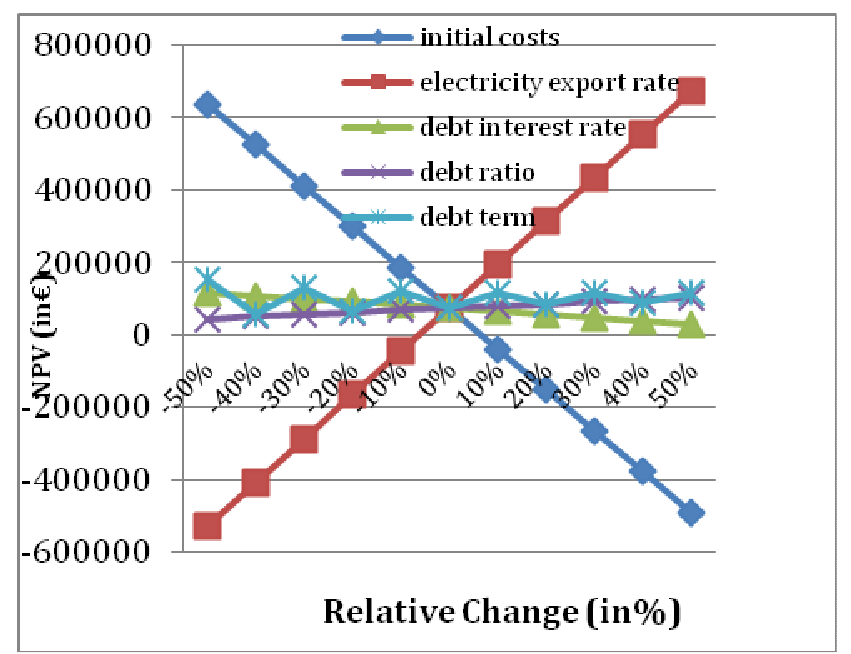

Fig. 8. Risk analysis for solar power project 
Similar to the earlier approach, the effect of best and worst scenarios are simulated to show the resulting effect on NPV of the project. In order to obtain the figures in Table 7 , the risk capacity of the initial costs and the electricity export rate are kept unchanged.

Table 7. Sensitivity analysis of solar power project

\begin{tabular}{|c|c|}
\hline Scenarios & NPV value \\
\hline $\begin{array}{l}\text { Best case } \\
\begin{array}{l}\text { - } \\
\text { - } \\
\quad \text { Electritial costs : }-20 \% \\
+5 \%\end{array}\end{array}$ & $358859 €$ \\
\hline $\begin{array}{l}\text { Worst case } \\
\begin{array}{l}\text { - Initial costs : }+20 \% \\
\text { - Electricity export rate : } \\
-5 \%\end{array}\end{array}$ & $-211959 €$ \\
\hline
\end{tabular}

These scenarios represent either a loss or a benefit of $285,409 €$ compared to the proposed case $(73,450 €)$. The project will not be financially feasible in the case of an increase of $20 \%$ in initial costs and a decrease in feed-in tariff rates. Thus if the project moves to the next stage, a careful evaluation of the initial costs must be carried out, and a fixed feed-in tariff rate must be secured for the project duration. If not, the project might have a risk of not meeting the NPV values simulated in our case study. In the case of photovoltaic panels, initial investment costs as well as incentives from the government are paramount in the subsequent success or failure of the project.

\section{ALTERNATIVE SCENARIOS}

In our feasibility assessment, we have simulated several case scenarios based on our evaluation of the current situation in Thira. The case studies presented earlier encompass the current situation of the electricity coming from a small diesel power plant on the island, or from a stand alone diesel power supply to the desalination unit. However, the Greek Government has plans to connect all the islands to the central grid mainland by an undersea cable. This would allow for renewable energy generation on the islands to be sold to the central grid at attractive feed-in tariff rates. The start of this initiative will be in 2012 [6]. In order to simulate this scenario, we have modelled additional case studies of:

Case Study 3: On Grid Wind Turbines

Case Study 4: On Grid Solar Panels

For these case studies we have used a feed in tariff rate of 99.45€/MWh for electricity from wind turbines and $394.89 € / \mathrm{MWh}$ for electricity from solar panels in our simulations [7].

In both case studies the projects were found to be not feasible. In case study 3 where the turbines sell excess electricity generated to the grid, the project had a payback period of 17.6 years and a NPV of -191001 euros because of a combination of insufficiently high feed-in tariff rates and high investment costs. In case study 4 , the project with solar panels exporting excess electricity to the grid, the NPV was even lower and the project subsequently not feasible.

The main focus of the project is to supply electricity for the desalination unit and not to maximize income from renewable electricity generation.

The reasons why these scenarios were not feasible can be explained by the following factors:

- $\quad$ Limited area to install solar panels or wind turbines. Land use for the project can only be justified up to the point where the energy requirement of the desalination unit is met.

- $\quad$ Extremely high initial investment costs in the case of solar panels.

- Comparatively low feed-in tariff rates for electricity generated by wind turbines.

- $\quad$ No subsidies for initial investment costs of renewable energy projects from the Greek Government.

- Constant operation of the desalination unit and no possibility to sell electricity to the grid when the costs are higher due to high demand.

- $\quad$ Electricity from the grid is cheaper than electricity generated from renewable energy resources.

- $\quad$ From the outcome of these case studies we have prepared some recommendations that can be addressed by Greek policy and incentives from the government in order to support similar renewable energy projects. These have been detailed in the conclusion section.

\section{Conclusion And Recommendations}

This project has been successful in proposing a solution to the resource shortage of water and limited access to electricity supply in the island of Thira by selecting the proper RES/ desalination combination using technical and economic criteria. The information derived from the various case studies presented would be extremely useful when formulating policies for renewable energy development or to make decisions for supporting renewable energy desalination.

The project location has renewable energy resources which are identical to that present in several other locations in the Mediterranean region thus, the results of this project can be easily applied to these other sites in order to evaluate if renewable energy desalination is a feasible solution.

The evaluated case studies demonstrated that wind energy utilization for desalination is the best solution for the islands in the Aegean Sea that face water shortage problems. Solar energy is also feasible, however the project will have a longer payback period.

If Thira is connected with the central grid in the future, the Greek Government needs to provide more support for 
renewable energy projects, especially for those with small-scale production to enable them to become economically feasible.

Considering the results obtained from our simulated scenarios, below are some recommendations:

- Subsidies for solar panels, which would enable significant reduction on initial investment costs.

- Increase in feed-in tariff rates for electricity from wind turbines.

- $\quad$ Cost of electricity should be dependent on different time periods, based on demand and supply.

- $\quad$ Cost of grid electricity produced from fossil fuels should be increased proportionately to the actual cost of production, and not subsidized by the government.

- Special subsidies for industries that produce their own electricity from renewable energy sources to supply their electricity requirements.

- $\quad$ The government should fund cost of grid connections from renewable energy plants to the main grid.

Recommendations for the water supply include pricing of the potable water supply at actual costs and regulated subsidies should be offered by the government to reduce the cost of water.

Other policies to minimize water waste and rational use of water resources should be implemented.

Since this area has a high number of tourists, it is important to ensure that the users and not the Greek Government bare the costs of supplying water.

It is also important to make sure suitable policies are in place to prevent pollution due to brine disposal and other impacts cause by constructing desalination units.

The next stage for our proposed case studies would be a detailed feasibility study, analysis of initial investment costs, surveys of the location, determination of exact locations and partnership with the Greek Government to obtain suitable incentives and subsidies.

\section{Acknowledgements}

The successful undertaking of this project would not have been possible without the assistance of our tutor Prof. Luis ROJAS from Simon Bolivar University who guided us and mentored us keeping a constant support to our team and to whom we are very grateful.

We also would like to thank Prof. Maxime PONTIE from Angers University and Jerome LEARC for their technical support.

We thank Florent CHAZARENC, coordinator of the ME3 Master's program.

Prof. Luis ROJAS thanks FONACIT-Venezuela, for funding his participation in ICREPQ'12, under agreement PC No. 201200292/No.112-004.

\section{Bibliography}

[1]Vörösmarty CJ, Green P, Salisbury J, Lammers RB. Water stress in to today's and tomorrow's world. Global water resources: vulnerability from climate change and population growth. . Science 289:284-8, 2001.

[2]National Aerospace Agency. Surface meteorology and Solar Energy. 26 March 2008. 15 March 2011 <http://eosweb.larc.nasa.gov/sse/RETScreen/>.

[3] Chaudhary A., Bishnoi P., Kumar Rout T., Analysis of Desalination of Water by Reverse Osmosis.

[4] Tzen E., Overview of the desalination technologies powered by renewable energies, CRES.

[5] European Environment Agency.Water resources across Europe, 2011 <http://www.eea.europa.eu>.

[6] Connecting Cyclades Network to mainland Greece.

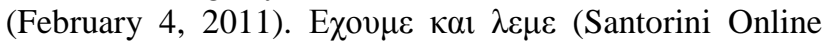
Newspaper).

[7] 2006-2011. Europe's Energy Portal. 2011 <www.energy.eu> 